\title{
Catalytic Performance of Nickel Nanowires Immobilized in Silica Aerogels for the $\mathrm{CO}_{2}$ Hydration Reaction
}

\author{
Khalil T. Hassan, ${ }^{*},{ }^{\dagger},{ }^{\dagger}$ Jiabin Wang, ${ }^{\dagger}$ Xiao Han, ${ }^{\dagger}$ Jon J. Sharp, ${ }^{\dagger}$ Gaurav A. Bhaduri, ${ }^{\dagger}$ Vladimir Martis, ${ }^{\S}$ \\ and Lidija Siller*, ${ }^{*}$ \\ ${ }^{\dagger}$ School of Engineering, Newcastle University, Newcastle upon Tyne NE1 7RU, U.K. \\ ${ }^{\ddagger}$ Department of Physics, College of Science, University of Anbar, Ramadi, Iraq \\ ${ }^{\S}$ Surface Measurement Systems Ltd, Unit 5, Wharfside, Rosemont Road, London HA0 4PE, U.K.
}

Supporting Information

\begin{abstract}
In this work, wavy nickel nanowires (NiNWs) were immobilized on mesoporous silica $\left(\mathrm{SiO}_{2}\right)$ aerogels by the sol-gel method. We measured the catalytic activity of pure $\mathrm{NiNWs}$ and $\mathrm{NiNW}-\mathrm{SiO}_{2}$ aerogel composites toward the $\mathrm{CO}_{2}$ hydration reaction (CHR) when they are in water. Dynamic vapor sorption (DVS) analysis was performed at levels of $50 \% \mathrm{CO}_{2}$ and $50 \% \mathrm{H}_{2} \mathrm{O}$ vapor for $\mathrm{SiO}_{2}$ aerogels, immobilized nickel nanoparticles (NiNPs) on silica aerogel and NiNW$\mathrm{SiO}_{2}$ aerogel composites, in order to determine catalytic activity for CHR in the gaseous phase. The results from DVS analysis (gaseous phase) and CHR (aqueous phase) showed that $\mathrm{NiNW}-\mathrm{SiO}_{2}$ aerogel composites are good heterogeneous catalysts for $\mathrm{CHR}$ in both gaseous and aqueous phases but they are less active than $\mathrm{NiNP}-\mathrm{SiO}_{2}$ aerogel composites.
\end{abstract}

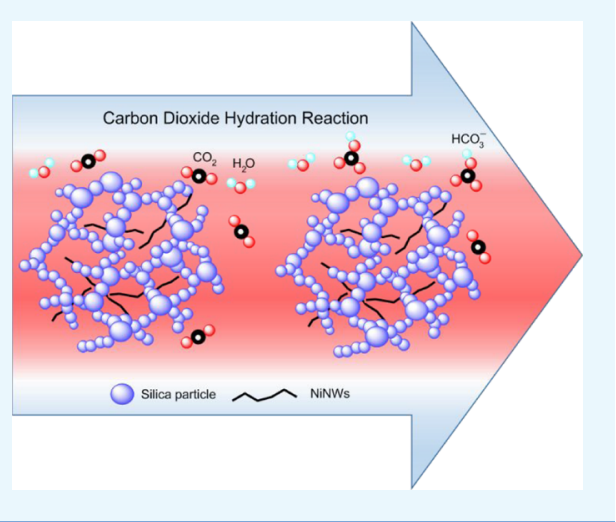

\section{INTRODUCTION}

The rise in atmospheric carbon dioxide $\left(\mathrm{CO}_{2}\right)$ is a major factor responsible for increasing global surface temperature. ${ }^{1,2}$ In efforts to hold the increase of the global temperature below 2 ${ }^{\circ} \mathrm{C}$, a multinational agreement was made in Paris to control $\mathrm{CO}_{2}$ emissions, however this might be inadequate. ${ }^{3}$ A possible solution to mitigate climate change is $\mathrm{CO}_{2}$ capture, storage, and utilization (CCSU). CCSU is a long-term solution to control the emission of greenhouse gases and to reduce the anthropogenic impact on the climate. ${ }^{4-7}$

Many technologies such as absorption, desorption, chemical looping combustion, membrane separation, hydrate-based separation, and cryogenic distillation have been developed to isolate $\mathrm{CO}_{2}$ from flue gas streams. ${ }^{8}$ Another promising CCSU technology is removing the $\mathrm{CO}_{2}$ by utilizing the $\mathrm{CO}_{2}$ hydration reaction (CHR). However, in the absence of a catalyst, the reaction is slow. In published literature, carbonic anhydrase (CA) is regarded as a suitable catalyst to accelerate $\mathrm{CO}_{2}$ mineralization reactions via the transformation of $\mathrm{CO}_{2}$ (aq) into bicarbonate $\left(\mathrm{HCO}_{3}{ }^{-}\right)$, as the $\mathrm{CHR}^{9-12}$ The core active site in CA is zinc, ${ }^{13}$ which is located in the center of metalloenzyme, and in the presence of $\mathrm{CA}, \mathrm{CO}_{2}$ hydration equilibrium can be rapidly reached, with zinc-bound $\mathrm{OH}$ reacting with dissolved $\mathrm{CO}_{2}$ to form bicarbonate. Other catalysts that are used for HRC include hypobromous acid ( $\mathrm{HOBr}),{ }^{14}$ hypochlorous acid ( $\left.\mathrm{HClO}\right)$, and boric acid. ${ }^{15,16}$ In the previous work by Šiller et al., ${ }^{17-19}$ nickel nanoparticles (NiNPs) have been demonstrated to possess catalytic activity to accelerate $\mathrm{CHR}$ as a first wholly inorganic heterogeneous catalyst. Major active catalysts are active in the alkaline range, whereas NiNP catalysts show that these are $\mathrm{pH}$ independent. ${ }^{17-19}$ This makes them as good candidates for saline aquifers that are typically acidic. ${ }^{20}$ NiNPs are also photocatalytically active toward the hydration reaction of $\mathrm{CO}_{2},{ }^{21}$ and can be extracted magnetically from solutions. Their nanotoxicity have been investigated on exposing a model environmental marine organism, sea urchins, to different concentrations of NiNP solutions, ${ }^{22}$ and it is shown that NiNPs are typically 10 times less toxic when compared to silver nanoparticles. In order to mitigate an environmental leaching of nickel ions into the water from NiNPs, very efficient absorbers have been developed and tested. ${ }^{23}$ After this work, theoretical investigations show that there are other metallic transition-metal catalysts active to CHR; ${ }^{24}$ however, NiNPs are still the most economical and/or chemically stable in waterbased environments.

Often the difference in surface area and surface structure because of different dimensionalities of nanomaterials, could also affect their catalytic activity. Therefore, here we have investigated immobilized nickel nanowires (NiNWs) as 1D nanomaterials in $\mathrm{SiO}_{2}$ aerogels as a heterogeneous catalyst for the CHR and compared them with NiNPs (as OD nanomaterials). Here, we study the difference in catalytic activity for $\mathrm{CHR}$ in a vapor phase when two different forms of nickel

Received: November 30, 2018

Accepted: December 24, 2018

Published: January 23, 2019 
nanomaterials (NiNPs and NiNWs) are immobilized in silica aerogels, which has not been studied previously, but only it was reported as the enhanced catalytic activity of NiNPs for CHR in aqueous solutions. ${ }^{19}$ The catalytic activity in a vapor phase by the cosorption at high concentration levels of $\mathrm{CO}_{2}$ and water was studied by adsorption-desorption kinetics and isotherms with a dynamic vapor sorption analyzer (DVS Vacuum).

\section{EXPERIMENTAL SECTION}

Materials. Nickel chloride hexahydrate $\left(\mathrm{NiCl}_{2} \cdot 6 \mathrm{H}_{2} \mathrm{O}\right)$, hydrazine hydrate $\left(\mathrm{N}_{2} \mathrm{H}_{4} \cdot \mathrm{H}_{2} \mathrm{O} ; 80\right.$ wt \%), ethylene glycol (EG) anhydrous $(99.8 \%)$, sodium hydroxide ( $\geq 98 \%)$, hexane ( $\geq 97.0 \%)$, tetramethylorthosilicate (TEOS $98 \%$ ), ammonium hydroxide $(28-30 \%)$, and ammonium fluoride $(\geq 98 \%)$ were supplied by Sigma-Aldrich. Ethanol (99.99\%) was purchased from Fisher Scientific. $\mathrm{CO}_{2}$ (99\%) was bought from BOC. All chemicals were used as received without further purification. Deionised (DI) water of a resistivity of $18 \mathrm{M} \Omega \mathrm{cm}^{-1}$ was used for preparation of solutions and washing.

Synthesis of NiNWs. NiNWs were synthesized following solvothermal process as previously reported by Chen et al. ${ }^{25}$ with a modification. Typically, $137 \mathrm{mg}$ of $\mathrm{NiCl}_{2} \cdot 6 \mathrm{H}_{2} \mathrm{O}$ was first added to $60 \mathrm{~mL}$ of $\mathrm{EG}$ in a round bottom flask. After $\mathrm{NiCl}_{2}$. $6 \mathrm{H}_{2} \mathrm{O}$ had fully dissolved in EG, $5 \mathrm{~mL}$ of $1 \mathrm{M} \mathrm{NaOH}$ and 2.3 $\mathrm{mL}$ of $\mathrm{N}_{2} \mathrm{H}_{4} \cdot \mathrm{H}_{2} \mathrm{O}$ were then added into this solution. This solution after been kept in a water bath at $60{ }^{\circ} \mathrm{C}$ for $3 \mathrm{~h}$, turned black indicating synthesis of NiNWs. NiNWs were first washed with DI water followed by washing with ethanol to remove residual reactants and solvent from the surface. Finally, NiNWs were dried in an oven at $60{ }^{\circ} \mathrm{C}$ for $8 \mathrm{~h}$. However, when these nanowires were suspended in DI water, the $\mathrm{pH}$ of the suspension was acidic because of the presence of residual reactants on the surface of NiNWs. Additional purification with $6 \mathrm{M} \mathrm{NaOH}$ was conducted to make NiNWs catalytically active, that is, until NiNW suspension had near neutral $\mathrm{pH}$ (for further details see Supporting Information).

Immobilization of NiNPs and NiNWs on Silica Aerogels. In this work, we prepared a $700 \mathrm{ppm}$ of NiNPs in silica aerogels synthesized by following Han et al. ${ }^{26}$ sample called Np. Sol-gel process is also used to synthesize the silica aerogel with the immobilization of NiNWs, according to the above synthesis process. ${ }^{26}$ In brief, NiNWs were dispersed during the sol stage prior to gelation so that silica aerogel samples with $0,400,500$, and $700 \mathrm{ppm}$ concentration of NiNWs (samples are called S, N1, N2, and N3 in Table 1, respectively) were synthesized. Typically, the desired amount of NiNWs were suspended in $5 \mathrm{~mL}$ of DI water using a sonic horn (Sonoplus, Bandelin) for $2 \mathrm{~min}$. Hydrolysis of TEOS in ethanol and DI water to prepare the silica gel was carried out with a molar ratio of 2:38:33 of TEOS/ethanol/water. To accelerate the gelation process, $1 \mathrm{~mL}$ mixture of ammonium hydroxide, ammonium fluoride, and DI water in a molar ratio 1:8:111 was used as a catalyst. Subsequently, the mixture was stirred and poured into a plastic mold for gelation. When gelation was completed (typically after $5 \mathrm{~min}$ ), the mold was removed and the gel was soaked in ethanol for aging. After 24 $h$, the ethanol solvent was replaced by hexane. The hexane was refreshed every $24 \mathrm{~h}$ for three days. Finally, the gel was dried at room temperature for $24 \mathrm{~h}$. After which, the gel was transferred to an oven for $8 \mathrm{~h}$ at $60{ }^{\circ} \mathrm{C}$, and in the final step, the temperature was further increased to $100{ }^{\circ} \mathrm{C}$ for additional $2 \mathrm{~h}$.
Table 1. Surface Area and Pore Size and Pore Volume Properties of NiNW, NiNP Composites and NiNW Composites (Pure Nickel Nanowires (No), Pure Silica Aerogel (S), 700 ppm of NiNPs in Silica Aerogel (Np), 400 ppm of NiNWs in Silica Aerogel (N1), 500 ppm of NiNWs in Silica Aerogel (N2), and 700 ppm of NiNWs in Silica Aerogel (N3))

\begin{tabular}{cccccc} 
sample & $\begin{array}{c}\text { NiNWs } \\
\text { wt } \%\end{array}$ & $\begin{array}{c}\text { NiNPs } \\
\text { wt } \%\end{array}$ & $\begin{array}{c}\text { surface } \\
\text { area } \\
\left(\mathrm{m}^{2} / \mathrm{g}\right)\end{array}$ & $\begin{array}{c}\text { pore specific } \\
\text { volume }\left(\mathrm{cm}^{3} / \mathrm{g}\right)\end{array}$ & $\begin{array}{c}\text { average } \\
\text { diameter } \\
(\mathrm{nm})\end{array}$ \\
N0 & 100 & & 9.3 & & \\
S & & & 509 & 1.48 & 17.3 \\
Np & & 3.25 & 515 & 1.61 & 11.6 \\
N1 & 0.5 & & 421 & 1.8 & 30.16 \\
N2 & 0.6 & & 410 & 1.54 & 25.6 \\
N3 & 1.25 & & 470 & 1.22 & 23.64 \\
\hline
\end{tabular}

Characterizations. The morphology of pure NiNW and $\mathrm{NiNW}-\mathrm{SiO}_{2}$ aerogel composites was studied using transmission electron microscopy (TEM, Philips CM-100) and scanning electron microscopy (SEM, Hitachi SU 8230), respectively. Nitrogen adsorption-desorption isotherm tests were characterized using a Thermo Scientific SURFER analyzer. Before conducting the test, the samples were outgassed under vacuum at $200{ }^{\circ} \mathrm{C}$ for $6 \mathrm{~h}$. Specific surface areas and pore size distribution of aerogels were calculated from isotherms using Brunauer, Emmett and Teller (BET) and Barrett-Joyner-Halenda (BJH) methods, respectively. X-ray diffraction (XRD) patterns of samples were recorded by the Panalytical X'Pert Pro Multipurpose Diffractometer with a wavelength of $0.15418 \mathrm{~nm}$ of $\mathrm{Cu} \mathrm{K} \alpha \mathrm{X}$-ray. Additionally, XRD was used to quantify the weight percentage of NiNWs inside silica aerogel composites by mixing a 20 wt \%-powdered $\mathrm{NiNW}-$ silica aerogel composite with 80 wt \% of aluminium oxide powder as the standard material. A fluidized-bed bubble glass column reactor was used to investigate the catalytic activity of $\mathrm{NiNWs}-\mathrm{SiO}_{2}$ aerogel composites for $\mathrm{CHR}$ in the aqueous phase. A vacuum dynamic gravimetric vapour sorption instrument (DVS Vacuum) was used to perform binary water vapour $/ \mathrm{CO}_{2}$ sorption measurements (see Supporting Information, Scheme S1).

\section{RESULTS AND DISCUSSION}

TEM images (see Supporting Information, Figure S1a,b) show the wavy shape of the NiNWs, which is similar to that reported by Chen et al. ${ }^{25}$ Wavy NiNWs have a nonuniform diameter (with the mean diameter $\approx 400 \mathrm{~nm}$ ) and $\approx 4 \mu \mathrm{m}$ in length. Figure S1c,d shows the TEM images for NiNPs. The particle diameter of NiNP in Figure S1d is $\approx 125 \mathrm{~nm}$, where TEM images (e) and (f) in Figure S1 show the porous structure of $700 \mathrm{ppm}$ NiNW-silica aerogel composite. The photo images of $\mathrm{NiNW}-\mathrm{SiO}_{2}$ aerogel composites (at 400, 500, and 700 $\mathrm{ppm})$ are presented in Figure $\mathrm{S} 2 \mathrm{~b}$ in the Supporting Information. The $\mathrm{N}_{2}$ adsorption-desorption isotherm of pure NiNWs is shown in the Supporting Information, Figure S3. The surface area of NiNWs was $9.3 \mathrm{~m}^{2} / \mathrm{g}$. $\mathrm{N}_{2}$ adsorptiondesorption isotherms of silica aerogel and $\mathrm{NiNW}-\mathrm{SiO}_{2}$ aerogel composites (see Supporting Information, Figure S4) show a type IV of isotherms and hysteresis loops of $\mathrm{H} 1$ type. According to IUPAC classification, the type IV isotherm indicates a mesoporous structure and $\mathrm{H} 1$ hysteresis loops are the characteristic of materials that exhibit a narrow range of 


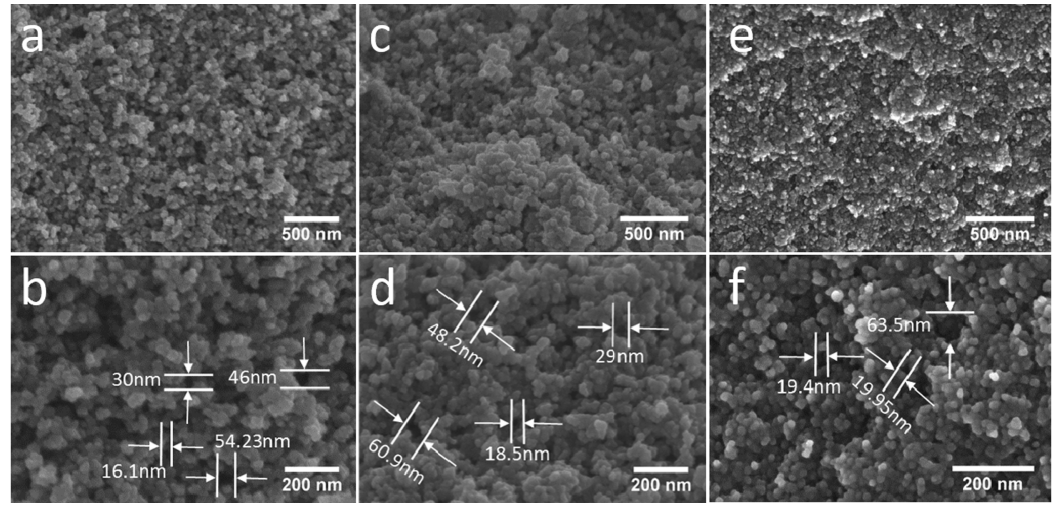

Figure 1. SEM images at different magnifications and different concentrations of NiNWs immobilized on $\mathrm{SiO}_{2}$ aerogels. (a and b) SEM images for $\mathrm{N1}$, (c and d) SEM images for N2, and (e and f) SEM images for N3. (Denotation: $400 \mathrm{ppm}$ of NiNWs in silica aerogel (N1), 500 ppm of NiNWs in silica aerogel (N2), and $700 \mathrm{ppm}$ of NiNWs in silica aerogel (N3)).

uniform mesopores. $^{27,28}$ A summary of surface area, pore volume, and pore diameter data is listed in Table 1 . The $\mathrm{SiO}_{2}$ aerogel alone has a surface area of $509 \mathrm{~m}^{2} / \mathrm{g}$. However, the surface area for the 400, 500, and $700 \mathrm{ppm} \mathrm{NiNW}-\mathrm{SiO}_{2}$ aerogel composites was found to be 421,410 , and $470 \mathrm{~m}^{2} / \mathrm{g}$, respectively. Surface area values for $\mathrm{NiNWs}-\mathrm{SiO}_{2}$ aerogel composites were similar because NiNWs act as a support for packing silica aerogels. Pore size distribution curves are shown in Figure S5 Supporting Information. These are determined from $\mathrm{N}_{2}$ desorption isotherms presented in Figure S4 by the $\mathrm{BJH}$ method. Most samples have mesoporous diameters with a broad pore size distribution. In addition, the pore volume (see Table 1) decreases with the increase of NiNW concentration inside silica aerogels. As expected, the pore specific volume for NiNWs in the silica aerogel (N3) is smaller than that for NiNPs in silica aerogels (Np) (see Table 1). Figure S6 Supporting Information shows XRD patterns from NiNW and $\mathrm{NiNW}-\mathrm{SiO}_{2}$ aerogel composites. The border peak around $2 \theta$ $=20^{\circ}$ in Figure S6 in the Supporting Information is for amorphous silica. The three characteristic peaks observed at $2 \theta$ $=44.58,51.9$, and $76.5^{\circ}$ correspond to nickel with Miller indices (111), (200), and (220), respectively, indicating the pure face center cube structure of the NiNWs. ${ }^{29}$ No other peaks suggesting oxidization were recorded which mean high purity of synthesis has been obtained. ${ }^{29}$ The XRD pattern of NiNWs immobilized in silica aerogels was also observed in Figure S6 Supporting Information. The quantification of NiNW and NiNP weight percentages (wt \%) in silica aerogels is presented in Table 1.

SEM images of $\mathrm{NiNW}-\mathrm{SiO}_{2}$ aerogel composites (Figure $1 \mathrm{a}-\mathrm{f})$ confirm the mesoporous nature of the support as obtained by BJH analysis (Figure S5 in Supporting Information). An estimation of the pore diameters from SEM images shows that the majority of pore diameters is in the range between 20 and $40 \mathrm{~nm}$. However, some macropores $(>50 \mathrm{~nm})$ are observed for the N3 sample. The presence of macropores in porous materials enhances the diffusion of gases through pores and therefore enhances $\mathrm{CO}_{2}$ capture. ${ }^{30,31}$

$\mathrm{CO}_{2}$ Dissolution. Figure $\mathrm{S} 7$ in the Supporting Information shows $\mathrm{CO}_{2}$ dissolution in DI water and in NiNW suspensions (details of experiments are given in Supporting Information). We plot the average values of the increase in saturation concentration of $\mathrm{CO}_{2}$ dissolved in DI water and with suspended NiNWs in DI water as a function of the concentration of nanowires, taken at room temperature and atmospheric pressure. The maximum uptake of $\mathrm{CO}_{2}$ is at a NiNW concentration of $\approx 30 \mathrm{ppm}$. The amount of $\mathrm{CO}_{2}$ dissolved in water without NiNWs was similar to that reported in the literature $(\approx 39 \mathrm{mM}){ }^{32}$ Therefore, further $\mathrm{pH}$ change analysis was performed in suspensions with a NiNW concentration at $\approx 30 \mathrm{ppm}$.

Catalytic and NonCatalytic CHR. Figure 2 shows pH changes during bubbling of carbon dioxide through DI water,

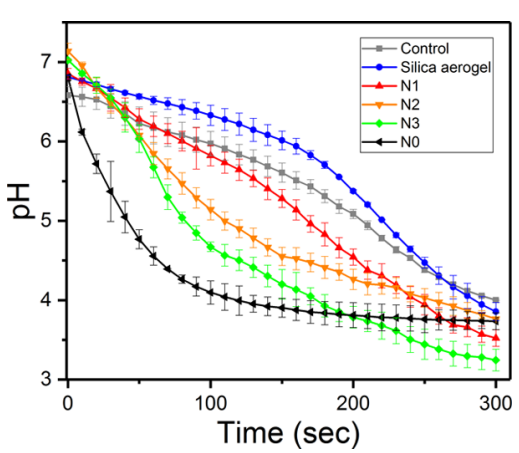

Figure 2. $\mathrm{pH}$ changes during bubbling of $\mathrm{CO}_{2}$ through $\mathrm{DI}$ water (grey), NiNW suspension (N0-black), $\mathrm{SiO}_{2}$ aerogel suspension (blue), and $\mathrm{Ni}$ nanowire- $\mathrm{SiO}_{2}$ aerogel composites at 400 (N1-red), 500 (N2-orange), and 700 ppm (N3-green). All experiments are performed at RT and atmospheric pressure.

including the silica aerogel-supported or freely suspended NiNW catalyst in a fluidized bed bubble column reactor. All experiments are taken at room temperature and atmospheric pressure. DI water was used as a control to observe the effectiveness of catalysts toward CHR. Silica aerogels alone do not catalyze the CHR (see grey and blue curves in Figure 2). The three supported catalysts at different NiNW concentrations (N1, N2, and N3, see Table 1), all show catalytic activity for CHR; however, they are less effective when compared to freely suspended NiNWs. We observe enhancement in the catalytic activity of $\mathrm{NiNWs}-\mathrm{SiO}_{2}$ aerogel composites as a function of NiNW concentration that is $\mathrm{N}_{1}$ $<\mathrm{N}_{2}<\mathrm{N}_{3}$. This is because of $\mathrm{CO}_{2}$ mass-transfer limitations created by the small size of the pores in silica aerogels. Another reason for the loss in activity could be because of a loss of active sites on NiNWs, as freely suspended NiNWs have higher active surface area than immobilized NiNWs in silica aerogels. 

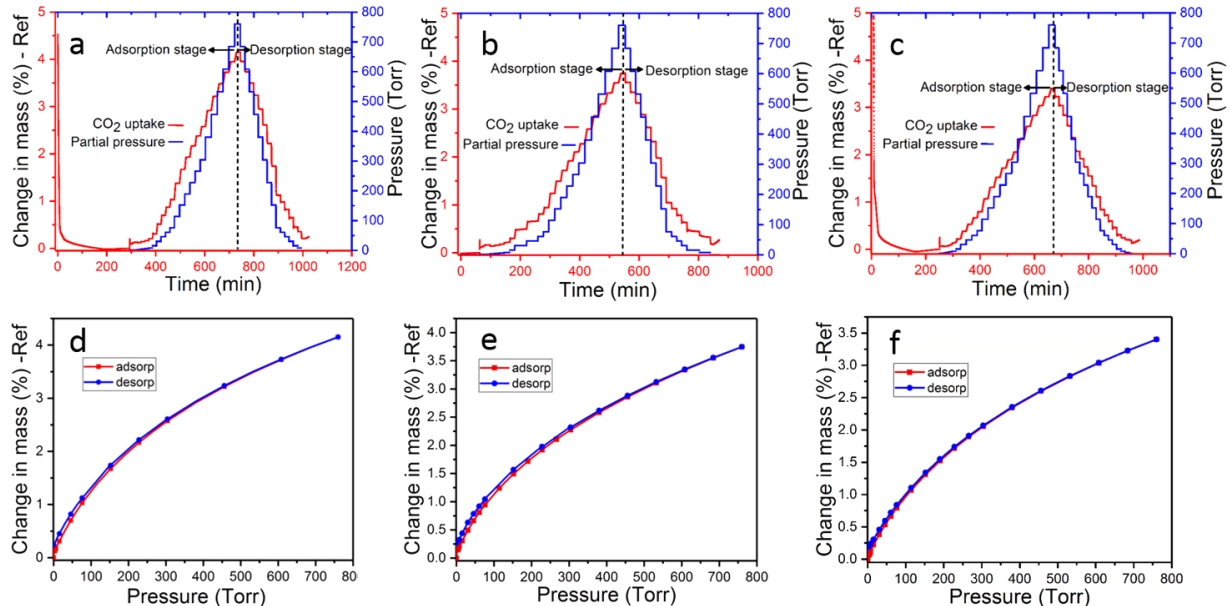

Figure 3. Adsorption-desorption cycles and adsorption-desorption isotherms showing $\mathrm{CO}_{2}$ sorption kinetics at $25{ }^{\circ} \mathrm{C}$. (a) Sorption kinetics for $\mathrm{SiO}_{2}$ aerogels, (b) sorption kinetics for $700 \mathrm{ppm} \mathrm{NiNP}-\mathrm{SiO}_{2}$ aerogel composites, (c) sorption kinetics for $700 \mathrm{ppm} \mathrm{NiNW}^{-} \mathrm{SiO}{ }_{2}$ aerogel composites, (d) adsorption-desorption isotherm curves of $\mathrm{SiO}_{2}$ aerogels, (e) adsorption-desorption isotherm curves of $700 \mathrm{ppm} \mathrm{NiNP}-\mathrm{SiO}_{2}$

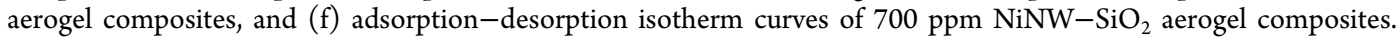
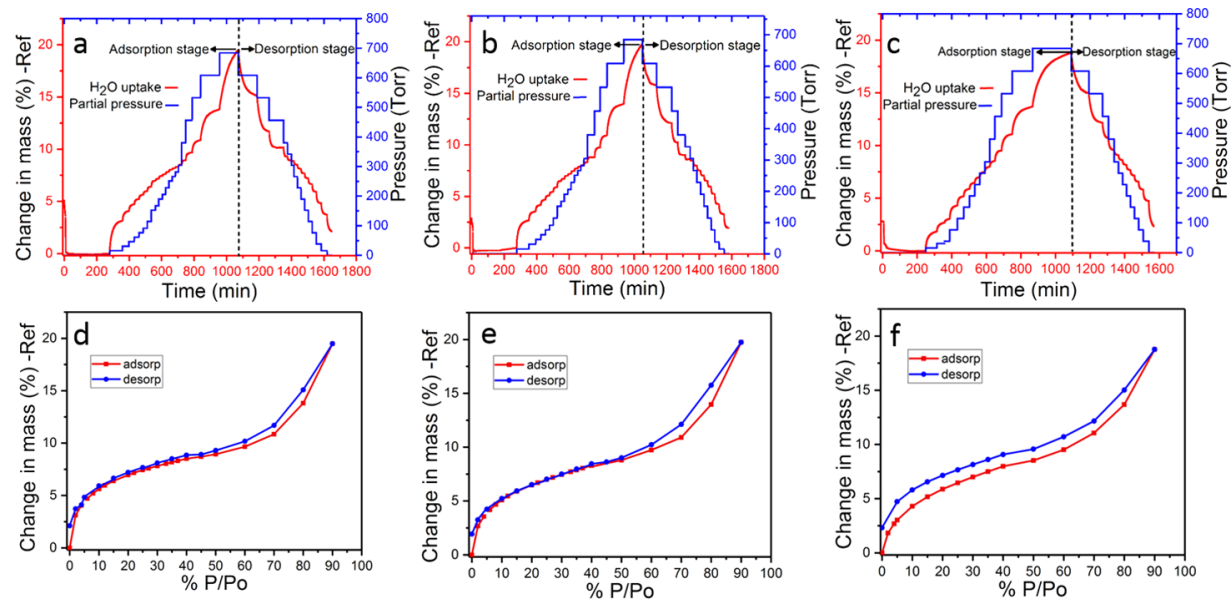

Figure 4. Adsorption-desorption cycles and adsorption-desorption isotherms showing $\mathrm{H}_{2} \mathrm{O}$ vapor sorption kinetics at $25{ }^{\circ} \mathrm{C}$. (a) Sorption kinetics for $\mathrm{SiO}_{2}$ aerogels, (b) sorption kinetics for $700 \mathrm{ppm} \mathrm{NiNP}-\mathrm{SiO}_{2}$ aerogel composites, (c) sorption kinetics for $700 \mathrm{ppm} \mathrm{NiNW-SiO}$ aerogel composites, (d) adsorption-desorption isotherm curves of $\mathrm{SiO}_{2}$ aerogels, (e) adsorption-desorption isotherm curves of 700 ppm NiNP-

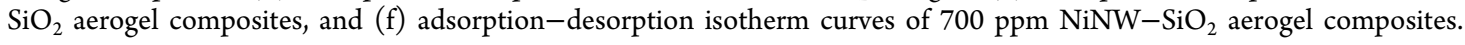

Dynamic Water Vapor/ $\mathrm{CO}_{2}$ Adsorption-Desorption Test. DVS was used to investigate the catalytic activity of immobilized NiNWs on $\mathrm{SiO}_{2}$ aerogels for CHR in the vapor phase. The experiments were performed on 700 ppm NiNW$\mathrm{SiO}_{2}$ aerogels, 700 ppm NiNP-SiO 2 aerogels, and pure $\mathrm{SiO}_{2}$ aerogels at same experimental conditions. Adsorptiondesorption curves were plotted based on mass equilibrium with time. Figure $3 \mathrm{a}-\mathrm{c}$ shows $\mathrm{CO}_{2}$ uptake cycles of $\mathrm{SiO}_{2}$ aerogel, 700 ppm NiNP-SiO ${ }_{2}$ aerogel, and 700 ppm NiNW$\mathrm{SiO}_{2}$ aerogel composites at $25{ }^{\circ} \mathrm{C}$, respectively. Adsorptiondesorption cycles (red line) are presented by changes in mass with time, whereas the blue line represents the relative pressure changes with time. All samples show capability of $\mathrm{CO}_{2}$ uptake. The adsorption capacities were 41.5, 37.5, and $34 \mathrm{mg}$ of $\mathrm{CO}_{2}$ per gram of adsorbent at $25{ }^{\circ} \mathrm{C}$ for pure silica aerogel, NiNP$\mathrm{SiO}_{2}$ aerogel composites, and $\mathrm{NiNW}-\mathrm{SiO}_{2}$ aerogel composites, respectively (see Table $\mathrm{S} 1$ in Supporting Information). Pure silica aerogels exhibit higher uptake capacity than NiNP$\mathrm{SiO}_{2}$ and $\mathrm{NiNW}-\mathrm{SiO}_{2}$ aerogel composites. However, the adsorption and desorption curves (Figure $3 \mathrm{~d}-\mathrm{f}$ ) were almost identical, meaning the process is approximately reversible (the desorption curve almost returns to the same point as at the start of the analysis). Consequently, no hysteresis loops were associated with the adsorption-desorption isotherms, indicating no tensile strength is applied to the pores. ${ }^{33}$ Water-vapor dynamic uptake curves (Figure $4 a-c$ ) of investigated materials demonstrated high interaction between water vapor molecules and the solid. It is widely accepted that the water adsorption mechanism includes four steps; (1) water adsorption on surface functional groups; (2) formation of a cluster of water molecules through adsorption because of the water molecules adsorbing on the previous adsorbed water molecules; (3) at a relative pressure (of approximately $P / P_{0}=0.5$ ) pore filling occurred, and (4) when the pressure becomes high, the pores are completely filled and the plateau is reached. ${ }^{34,35}$ A relatively high-water vapor adsorption capacities at $25{ }^{\circ} \mathrm{C}$ were recorded (194.5, 197.5 and $188 \mathrm{mg}$ of $\mathrm{H}_{2} \mathrm{O}$ per gram of adsorbent, for pure silica aerogels, $\mathrm{NiNP}-\mathrm{SiO}_{2}$, and $\mathrm{NiNW}-\mathrm{SiO}_{2}$ aerogel composites, respectively; see Table $\mathrm{S} 1$ in Supporting Information). Again, $\mathrm{NiNW}-\mathrm{SiO}_{2}$ aerogel composites showed lower water adsorption capacity than pure silica aerogel or $\mathrm{NiNP}-\mathrm{SiO}_{2}$ aerogel composites. It is likely that hydroxyl 

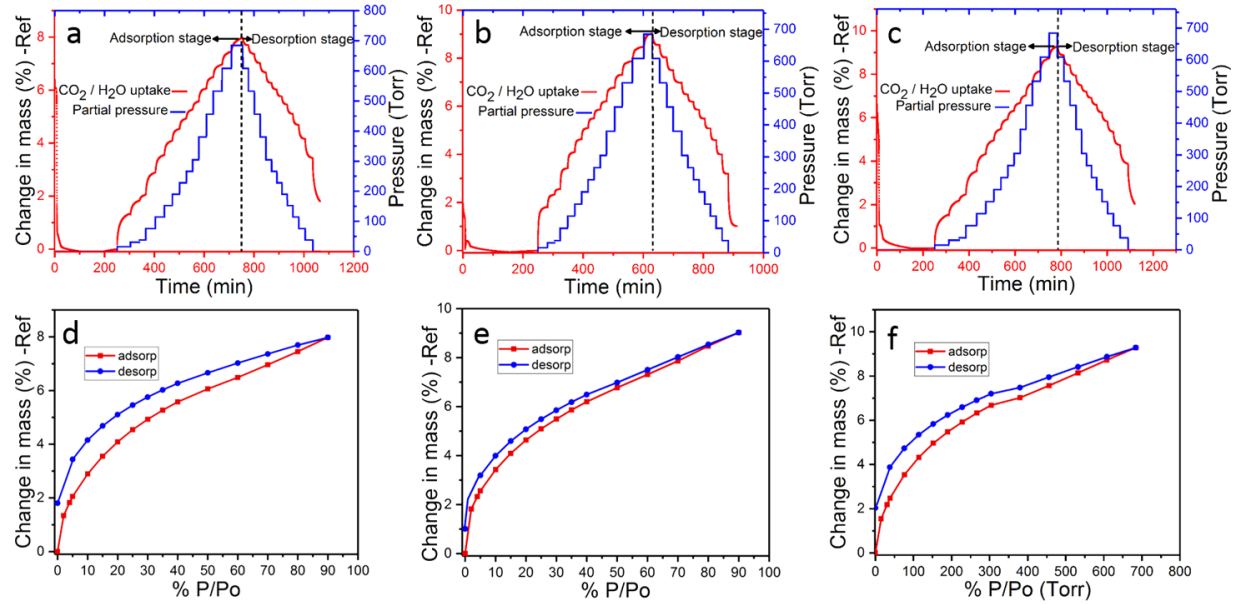

Figure 5. Adsorption-desorption cycles and adsorption-desorption isotherm curves showing $50 / 50 \mathrm{H}_{2} \mathrm{O} / \mathrm{CO}_{2}$ sorption kinetics at $25{ }^{\circ} \mathrm{C}$. (a) Sorption kinetics for $\mathrm{SiO}_{2}$ aerogels, (b) sorption kinetics for $700 \mathrm{ppm} \mathrm{NiNP}-\mathrm{SiO}_{2}$ aerogel composites, (c) sorption kinetics for 700 ppm NiNW$\mathrm{SiO}_{2}$ aerogel composites, (d) adsorption-desorption isotherm curves of $\mathrm{SiO}_{2}$ aerogels, (e) adsorption-desorption isotherm curves of 700 ppm $\mathrm{NiNP}-\mathrm{SiO}_{2}$ aerogel composites, and (f) adsorption-desorption isotherm curves of $700 \mathrm{ppm} \mathrm{NiNW-SiO}{ }_{2}$ aerogel composites.

groups at $\mathrm{SiO}_{2}$ aerogel surfaces via $\mathrm{H}$-bonding interact with water vapor molecules and work as adsorption sites. ${ }^{36}$ Formation of hysteresis loops (see Figure $4 \mathrm{~d}-\mathrm{f}$ ) is because of capillary condensation and formation of irreversible hydrate (capillary condensation is the dominated adsorption mechanism at the high level of humidity loading ${ }^{37}$ ). The isotherms were demonstrated as an open loop system (do not come back to zero), meaning some moisture is retained in solid matrices. In particular, water is more strongly bonded to $\mathrm{NiNW}-\mathrm{SiO}_{2}$ aerogel composites than $\mathrm{NiNP}-\mathrm{SiO}_{2}$ aerogel composites. The retention mass for NiNWs is larger than for NiNPs, see column 4 Table $S 1$ in the Supporting Information. Because NiNWs are wavy (see the TEM images in Figure $S 1$ in Supporting Information), there is larger number of defect sites on step edges, in which they will act as stronger bonding sites for water molecules.

Comparing the uptake of $\mathrm{CO}_{2}$ and water vapor for the different aerogel compositions, it was observed that NiNW$\mathrm{SiO}_{2}$ aerogel composites show the highest uptake for water vapor when compared to $\mathrm{CO}_{2}$ uptake $(188 / 34=5.5$ times higher). Figure 5 shows the cosorption cycles and isotherm behavior for investigated samples at gaseous volumetric mixture of $50 / 50 \mathrm{H}_{2} \mathrm{O} / \mathrm{CO}_{2}$. Adsorption behavior is similar to that observed for $\mathrm{H}_{2} \mathrm{O}$ in Figure 4. Isotherms have an open loop hysteresis and samples retain liquids (see Table S1 in Supporting Information, sixth column). Because there is a high level of humidity and $\mathrm{CO}_{2}$ during loading, water vapor could condense and form carbonic acid. ${ }^{37}$

$\mathrm{NiNW}-\mathrm{SiO}_{2}$ aerogel composite $\left(93 \mathrm{mg}\right.$ of $\mathrm{H}_{2} \mathrm{O} / \mathrm{CO}_{2} / \mathrm{g}$ adsorbent) and $\mathrm{NiNP}-\mathrm{SiO}_{2}$ aerogel composite (90 mg of $\mathrm{H}_{2} \mathrm{O} / \mathrm{CO}_{2}$ /g-adsorbent) exhibited higher adsorption capacity than pure silica aerogels (79.8 $\mathrm{mg}$ of $\mathrm{H}_{2} \mathrm{O} / \mathrm{CO}_{2} /$ g-adsorbent), see fifth number column in Table $\mathrm{S} 1$ in the Supporting Information.

The slopes of the linear part of adsorption curves in Figure 6 , the adsorption parts, for silica aerogel, NiNP-silica aerogel composites, and NiNW-silica aerogel composites are 0.088 , 01196, and 0.105, respectively. This change could be or because of different catalytic activities or because of different pore size diameters that could influence the flow rate of vapor through material. However, we see in Table T1 that the pore diameter of NiNWs-silica aerogel composites is much larger

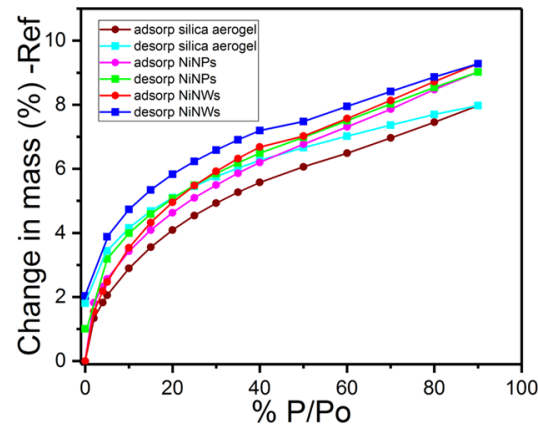

Figure 6. Comparison of $50 / 50 \quad \mathrm{H}_{2} \mathrm{O} / \mathrm{CO}_{2}$ adsorption (ads) and desorption isotherms (des) for $700 \mathrm{ppm} \mathrm{NiNP}-\mathrm{SiO}_{2}$ aerogel composites (ads is in pink and des is in green) and for 700 $\mathrm{NiNW}-\mathrm{SiO}_{2}$ aerogel composites (ads is in red and des is in blue) and pure silica aerogels (ads in brown and des in turquoise). Data are taken at $25{ }^{\circ} \mathrm{C}$.

than for NiNPs-silica composites which can rule out this second possibility. In addition because we have retention of water on NiNW-silica aerogel samples much larger than on NiNP-silica aerogels, this implies that the bonding of water molecules is stronger. Therefore, the changes in slope are because of changes in catalytic activities of NiNPs and NiNWs trapped in silica aerogels. The catalytic activity toward $\mathrm{CO}_{2}-$ $\mathrm{H}_{2} \mathrm{O}$ coadsorption is fastest on NiNP-silica aerogel composites, followed by NiNW-silica aerogel composites and then followed by silica aerogels.

The mechanism of adsorption-desorption of $\mathrm{H}_{2} \mathrm{O} / \mathrm{CO}_{2}$ vapor mixture on $\mathrm{Ni}$ nanowires could be similar to previous experimental $^{17,18}$ and theoretical work ${ }^{24}$ on NiNPs. Adsorption of $\mathrm{CO}_{2}$ and $\mathrm{H}_{2} \mathrm{O}$ molecules in the liquid phase is energetically favorable at the $\mathrm{Ni}$ surface when compared to the gas phase. ${ }^{24,38}$ The adsorption free energy of the $\mathrm{H}_{2} \mathrm{O}$ complex that is formed on the $\mathrm{Ni}$ surface was found to decrease from $9.95 \mathrm{kcal} / \mathrm{mol}$ in vacuum to $5.4 \mathrm{kcal} / \mathrm{mol}$ in the solvent state. ${ }^{24}$ This $\mathrm{H}_{2} \mathrm{O}$ dissociates into $\mathrm{OH}$ and $\mathrm{H}$ groups on the surface of $\mathrm{Ni}$ cluster, with the activation barrier for deprotonation found to be lower in the solvent state than in a vacuum. ${ }^{24}$ When $\mathrm{CO}_{2}$ molecules react with the surface of $\mathrm{Ni}$, a bent intermediate $\mathrm{CO}_{2} \delta^{-}$is formed and this transformation from the linear to 
bent structure is associated with a significant reduction in the activation energy barrier. ${ }^{39}$ When adsorbed $\mathrm{CO}_{2}$ molecules interact with hydroxyl groups to form a bent $\mathrm{OH}-\mathrm{CO}_{2}$ complex, the oxygen atom of the hydroxyl group can lose a proton to a $\mathrm{CO}_{2}$ oxygen atom forming a $\mathrm{Ni}-\mathrm{HCO}_{3}{ }^{-}$complex. As it is mentioned because of high capillary condensation, water vapor tends to be condensed in mesoporous $\mathrm{SiO}_{2}$ aerogels forming the liquid phase. The $\mathrm{HCO}_{3}{ }^{-}$complex would be released from the surface of $\mathrm{Ni}$ either by another water vapor molecule or directly dissolved in the generated water phase.

\section{CONCLUSIONS}

The results of catalytic activity analysis of wavy NiNWs and immobilized wavy NiNWs on silica aerogels for CHR that performed in the aqueous phase at room temperature exhibit enhancement in the rate of dissolution of carbon dioxide. The rate of carbon dioxide dissolution in the presence of supported NiNWs increased with the increase NiNW concentration. The best catalytic efficiency was seen when testing the NiNW$\mathrm{SiO}_{2}$ aerogel composite with a concentration of $700 \mathrm{ppm}$ NiNWs. The thermo gravimetric results that obtained from DVS showed that utilizing NiNWs as a heterogeneous catalyst promoted the catalytic activity for CHR, agreeing with the results found in the aqueous catalytic activity testing. However, NiNPs on the aerogel support are found to be better catalysts toward CHR than NiNW aerogel composites.

\section{ASSOCIATED CONTENT}

\section{S Supporting Information}

The Supporting Information is available free of charge on the ACS Publications website at DOI: 10.1021/acsomega.8b03361.

Purification of NiNWs, hydration test, vacuum dynamic vapour sorption (DVS), (TEM) images, NiNW-silica aerogels composites images, BET isotherms, (XRD) patterns, and $\mathrm{CO}_{2}$ saturation and catalytic activity figure (PDF)

\section{AUTHOR INFORMATION}

\section{Corresponding Authors}

*E-mail: k.t.hassan@newcastle.ac.uk

*E-mail: lidija.siller@newcastle.ac.uk

\section{Notes}

The authors declare no competing financial interest.

\section{ACKNOWLEDGMENTS}

K.T.H. would like to thank Higher Committee for Education Development in Iraq (HCED) for $\mathrm{PhD}$ scholarship. The authors thank Surface Measurement Systems UK Ltd for their assistance with DVS analysis. We would like to thank to EPSRC for a financial support (Grant no. EP/R000131/1). Data supporting this publication is openly available under an Open Data Commons Open Database License. Additional metadata are available at: http://dx.doi.org/10.17634/1650801.

\section{ABBREVIATIONS}

TEOS, tetraethylorthosilicate; NiNWs, nickel nanowires; NiNPs, nickel nanoparticles; SEM, scanning electron micros- copy; BET, Brunauer-Emmett-Teller; BJH, Barrett-JoynerHalenda; DVS, dynamic vapour sorption instrument

\section{REFERENCES}

(1) Betts, R. A.; Jones, C. D.; Knight, J. R.; Keeling, R. F.; Kennedy, J. J. El Niño and a record $\mathrm{CO}_{2}$ rise. Nat. Clim. Change 2016, 6, 806810.

(2) Linneen, N. N.; Pfeffer, R.; Lin, Y. S. $\mathrm{CO}_{2}$ adsorption performance for amine grafted particulate silica aerogels. Chem.Eng. J. 2014, 254, 190-197.

(3) Rogelj, J.; den Elzen, M.; Höhne, N.; Fransen, T.; Fekete, H.; Winkler, H.; Schaeffer, R.; Sha, F.; Riahi, K.; Meinshausen, M. Paris agreement climate proposals need a boost to keep warming well below $2{ }^{\circ} \mathrm{C}$. Nature 2016, 534, 631-639.

(4) Minju, N.; Abhilash, P.; Nair, B. N.; Mohamed, A. P.; Ananthakumar, S. Amine impregnated porous silica gel sorbents synthesized from water-glass precursors for $\mathrm{CO}_{2}$ capturing. Chem.Eng. J. 2015, 269, 335-342.

(5) Kong, Y.; Shen, X.; Fan, M.; Yang, M.; Cui, S. Dynamic capture of low-concentration $\mathrm{CO}_{2}$ on amine hybrid silsesquioxane aerogel. Chem.-Eng. J. 2016, 283, 1059-1068.

(6) Zhang, X.; Bao, D.; Huang, Y.; Dong, H.; Zhang, X.; Zhang, S. Gas-liquid mass-transfer properties in $\mathrm{CO}_{2}$ absorption system with ionic liquids. AlChE J. 2014, 60, 2929-2939.

(7) Zhang, W.; Liu, H.; Sun, C.; Drage, T. C.; Snape, C. E. Capturing $\mathrm{CO}_{2}$ from ambient air using a polyethyleneimine-silica adsorbent in fluidized beds. Chem.-Eng. J. 2014, 116, 306-316.

(8) Leung, D. Y. C.; Caramanna, G.; Maroto-Valer, M. M. An overview of current status of carbon dioxide capture and storage technologies. Renewable Sustainable Energy Rev. 2014, 39, 426-443.

(9) Vinoba, M.; Bhagiyalakshmi, M.; Grace, A. N.; Kim, D. H.; Yoon, Y.; Nam, S. C.; Baek, I. H.; Jeong, S. K. Carbonic Anhydrase Promotes the Absorption Rate of $\mathrm{CO}_{2}$ in Post-Combustion Processes. J. Phys. Chem. B 2013, 117, 5683-5690.

(10) Li, W.; Chen, W.-S.; Zhou, P.-P.; Zhu, S.-L.; Yu, L.-J. Influence of initial calcium ion concentration on the precipitation and crystal morphology of calcium carbonate induced by bacterial carbonic anhydrase. Chem. Eng. J. 2013, 218, 65-72.

(11) Power, I. M.; Harrison, A. L.; Dipple, G. M. Accelerating mineral carbonation using carbonic anhydrase. Environ. Sci. Technol. 2016, 50, 2610-2618.

(12) Power, I. M.; Harrison, A. L.; Dipple, G. M.; Southam, G. Carbon sequestration via carbonic anhydrase facilitated magnesium carbonate precipitation. Int. J. Greenhouse Gas Control 2013, 16, 145155

(13) Kim, M.-C.; Lee, S.-Y. Comparative study on the catalytic hydration of carbon dioxide by catalysts that mimic carbonic anhydrase prepared with zinc salts. ChemCatChem 2015, 7, 698-704.

(14) Hasting, M. K. H. B. The catalytic hydration of carbon dioxide. J. Biol. Chem. 1940, 132, 267-280.

(15) Ahmadi, M.; Gomes, V. G.; Ngian, K. Advanced modelling in performance optimization for reactive separation in industrial $\mathrm{CO}_{2}$ removal. Sep. Purif. Technol. 2008, 63, 107-115.

(16) Ghosh, U. K.; Kentish, S. E.; Stevens, G. W. Absorption of carbon dioxide into aqueous potassium carbonate promoted by boric acid. In Greenhouse Gas Control Technologies 9; Gale, J.; Herzog, H.; Braitsch, J., Eds.; Elsevier Science Bv: Amsterdam, 2009; Vol. 1, pp 1075-1081.

(17) Šller, L.; Bhaduri, G. A. Carbon Capture. GB132038.2 WO2013/171480 (A), 2013.

(18) Bhaduri, G. A.; Siller, L. Nickel nanoparticles catalyse reversible hydration of carbon dioxide for mineralization carbon capture and storage. Catal. Sci. Technol. 2013, 3, 1234-1239.

(19) Bhaduri, G. A.; Alamiry, M. A. H.; Šiller, L. Nickel nanoparticles for enhancing carbon capture. J. Nanomater. 2015, $2015,1-13$.

(20) Seo, S.; Perez, G. A.; Tewari, K.; Comas, X.; Kim, M. Catalytic activity of nickel nanoparticles stabilized by adsorbing polymers for enhanced carbon sequestration. Sci. Rep. 2018, 8, 11786. 
(21) Bhaduri, G. A.; Muzaffar, B.; Alamiry, M. A. H.; Yuan, J.; Shangguan, W.; Siller, L. Photochemical Enhancement in Catalytic Activity of Nickel Nanoparticles for Hydration of $\mathrm{CO}_{2}$. ChemistrySelect 2016, 1, 2091-2095.

(22) Kanold, J. M.; Wang, J.; Brümmer, F.; Šiller, L. Metallic nickel nanoparticles and their effect on the embryonic development of the sea urchin Paracentrotus lividus. Environ. Pollut. 2016, 212, 224-229.

(23) Salihi, E. Ç.; Wang, J.; Coleman, D. J. L.; Šiller, L. Enhanced removal of nickel(II) ions from aqueous solutions by SDSfunctionalized graphene oxide. Sep. Sci. Technol. 2016, 51, 13171327.

(24) Verma, M.; Sravan Kumar, K. B.; Deshpande, P. A. Computational Insights into the Activity of Transition Metals for Biomimetic $\mathrm{CO}_{2}$ Hydration. J. Phys. Chem. C 2016, 120, 5577-5584.

(25) Chen, L.; Fang, M.; Liu, C.; Liu, X.; Xing, S. Manipulating the nickel shape and catalytic performance: from spheres to chains to urchins. CrystEngComm 2015, 17, 4343-4348.

(26) Han, X.; Williamson, F.; Bhaduri, G. A.; Harvey, A.; Šiller, L. Synthesis and characterisation of ambient pressure dried composites of silica aerogel matrix and embedded nickel nanoparticles. J. Supercrit. Fluids 2015, 106, 140-144.

(27) Thommes, M.; Kaneko, K.; Neimark, A. V.; Olivier, J. P.; Rodriguez-Reinoso, F.; Rouquerol, J.; Sing, K. S. W. Physisorption of gases, with special reference to the evaluation of surface area and pore size distribution (IUPAC Technical Report). Pure Appl. Chem. 2015, $87,1051-1069$.

(28) Sing, K. S. W.; Everett, D. H.; Haul, R. A. W.; Moscou, L.; Pierotti, R. A.; Rouquerol, J.; Siemieniewska, T. Reporting physisorption data for gas/solid systems with special reference to the determination of surface area and porosity (recommendations 1984). Pure Appl. Chem. 1985, 57, 603-619.

(29) Wang, J.; Zhang, L. Y.; Liu, P.; Lan, T. M.; Zhang, J.; Wei, L. M.; Kong, E. S.-W.; Jiang, C. H.; Zhang, Y. F. Preparation and growth mechanism of nickel nanowires under applied magnetic field. NanoMicro Lett. 2010, 2, 134-138.

(30) Drese, J. H.; Choi, S.; Lively, R. P.; Koros, W. J.; Fauth, D. J.; Gray, M. L.; Jones, C. W. Synthesis Structure Property Relationships for Hyperbranched Aminosilica $\mathrm{CO}_{2}$ Adsorbents. Adv. Funct. Mater. 2009, 19, 3821-3832.

(31) Zeleňák, V.; Badaničová, M.; Halamová, D.; Čejka, J.; Zukal, A.; Murafa, N.; Goerigk, G. Amine-modified ordered mesoporous silica: effect of pore size on carbon dioxide capture. Chem. Eng. J. 2008, 144, 336-342.

(32) Favre, N.; Christ, M. L.; Pierre, A. C. Biocatalytic capture of $\mathrm{CO}_{2}$ with carbonic anhydrase and its transformation to solid carbonate. J. Mol. Catal. B: Enzym. 2009, 60, 163-170.

(33) Al-Janabi, N.; Hill, P.; Torrente-Murciano, L.; Garforth, A.; Gorgojo, P.; Siperstein, F.; Fan, X. Mapping the Cu-BTC metalorganic framework (HKUST-1) stability envelope in the presence of water vapour for $\mathrm{CO}_{2}$ adsorption from flue gases. Chem. Eng. J. 2015, 281, 669-677.

(34) Brennan, J. K.; Bandosz, T. J.; Thomson, K. T.; Gubbins, K. E. Water in porous carbons. Colloids Surf., A 2001, 187-188, 539-568.

(35) Chen, H.; Wang, W.; Wei, X.; Ding, J.; Yang, J. Experimental and numerical study on water sorption over modified mesoporous silica. Adsorption 2015, 21, 67-75.

(36) Wei, X.; Wang, W.; Xiao, J.; Zhang, L.; Chen, H.; Ding, J. Hierarchically porous aluminosilicates as the water vapor adsorbents for dehumidification. Chem. Eng. J. 2013, 228, 1133-1139.

(37) Li, G.; Xiao, P.; Webley, P.; Zhang, J.; Singh, R.; Marshall, M. Capture of $\mathrm{CO}_{2}$ from high humidity flue gas by vacuum swing adsorption with zeolite 13X. Chem. Eng. Sci. 2008, 14, 415-422.

(38) Xu, H.; Chu, W.; Sun, W.; Jiang, C.; Liu, Z. DFT studies of Ni cluster on graphene surface: effect of $\mathrm{CO}_{2}$ activation. RSC Adv. 2016, 6, 96545-96553.

(39) Ding, X.; Pagan, V.; Peressi, M.; Ancilotto, F. Modeling adsorption of $\mathrm{CO}_{2}$ on $\mathrm{Ni}(110)$ surface. Mater. Sci. Eng., C 2007, 27, 1355-1359. 